\title{
Inducible Clindamycin Resistance Among the Staphylococcus aureus Colonizing the Anterior Nares of School Children of Udupi Taluk
}

Govindan S 1, Mohammed AC ${ }^{2}$, Bairy I ${ }^{3}$

Senior Grade Lecturer, Department of Microbiology, Melaka Manipal Medical College, Manipal University,

Manipal

2 Professor, Department of Microbiology, Melaka Manipal Medical College, Manipal University, Manipal

${ }^{3}$ Professor, Department of Microbiology, Melaka Manipal Medical College, Manipal University, Manipal

\section{Chief Editor}

Dr. Indrajit Banerjee

Technical Editor

Dr. Nishida Chandrasekharan

Formatting Editor

Dr. Indrajit Banerjee

\section{Short Communication}

\section{Corresponding Author:}

Sreejith Govindan

Senior Grade Lecturer, Department of Microbiology

Melaka Manipal Medical College,

Manipal University, Manipal

E-mail:g.sreejith@manipal.edu

\section{Abstract}

Clindamycin is one of the preferred antibiotics in the treatment of Staphylococcus aureus (SA) skin and soft tissue infections. However the emergence of inducible clindamycin resistant $S A$ is a major concern for clinicians in the management of such infections. Information about such resistant strains of SA colonizing the anterior nares is very important in planning infection control strategies. The objective of the current study was to assess the proportion of SA showing inducible clindamycin resistance and also to know their association with methicillin resistance. Among the isolates, $11.6 \%(44 / 378)$ strains were showing positive $D$ test which indicates inducible clindamycin resistance and a highly significant $71 \%(12 / 17)$ inducible clindamycin resistance was also noticed in the case of MRSA. The nasal carriage of inducible clindamycin resistant SA showing a

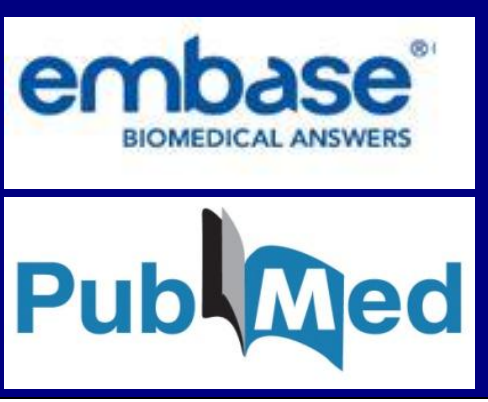

\section{This title is indexed in SciVerse Scopus \\ Improving research results through analytical power}

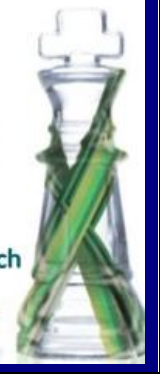

significant association with MRSA strains by the paediatric population from this area warrants the inclusion of $D$ test in the routine antibiotic susceptibility testing of SA isolates. Information about the MLSBi status among the colonizing strains would also help the public health authorities to plan and implement infection control strategies at the community level.

Keywords: Staphylococcus aureus, D test, Inducible clindamycin resistance, MRSA

\section{Background}

Macrolides, lincosamides and streptogramin B (MLSB) antibiotics inhibit protein synthesis in the bacteria by binding to ribosomal subunits and by interfering the elongation of amino acids ${ }^{1}$. Lincosamides like clindamycin were successfully used in treating skin and soft tissue infections caused by MRSA. But emergence of clindamycin resistance during therapy discouraged many clinicians continuing this treatment regime ${ }^{2}$.

Macrolide resistance in Staphylococcus aureus (SA) can be due to two reasons. ${ }^{3}$ One mechanism is by the action of an energy dependent pump that expels macrolides from the cell of bacteria before it acts on drug target ${ }^{3,4}$. This efflux pump is encoded by $\operatorname{msr}(\mathrm{A})$ gene ${ }^{5}$. This mechanism also results in resistance to group B streptogramins (eg. Quinupristin). This does not lead to resistance towards 
lincosamides (eg. Clindamycin). Second mechanism leads to resistance towards macrolides, lincosamides and streptogramins as well. This is commonly known as "MLSB resistance" ${ }^{4,6}$. This type of resistance results from reduction of affinity due to $\mathrm{N}$-6-dimethylation of an adenine residue in the $23 \mathrm{~S} \mathrm{rRNA}^{4}$. Methylation of this $23 \mathrm{~S}$ rRNA binding site is due to a methylase encoded by genes ermC and ermA.

MLSB resistance can be expressed constitutively (MLSBC phenotype) or when induced into its production (MLSBi phenotype) ${ }^{7}$. A strain that possess erm gene if exposed to macrolides, the binding of the drug molecules to target results in alteration of secondary structure of mRNA, exposure of the binding site and translation of erm methylase. These changes in bacteria lead to constitutive resistance to MLSB drugs ${ }^{7}{ }^{8}$. But the mechanism of resistance in $\mathrm{MLSBi}$ phenotype is different. They are intrinsically resistant to majority of the macrolides but shows in vitro susceptibility to lincosamides and group B streptogramins. However a macrolide inducer can convert such strains to lincosamide and streptogramin resistant ones. Some spontaneous mutations can also result in change of MLSBi stains to MLSBC strains and if it happens in the middle of a therapy that may lead to treatment failure ${ }^{3}$. This property of SA can be detected in laboratory by a method called D test. The stain that shows MLSBi resistance will produce a D shaped zone of inhibition around clindamycin disc ${ }^{2}$.

Nasal carriage is found to the major source for most of the community associated SA infections. So it is of great importance to know the antibiotic susceptibility pattern of such strains especially with respect to methicillin resistance and inducible clindamycin resistance. The present study was undertaken to know the level of inducible clindamycin resistance among the SA isolated from the anterior nares of school children. This study also assessed the association between inducible clindamycin resistance and methicillin resistant SA (MRSA).

\section{Material and Methods}

A total of 378 strains of SA isolated during June 2009 to December 2010 were used in the study. Originally those strains were isolated as a part of a prevalence study conducted by the same authors (unpublished). Institutional ethics committee clearance was obtained from Manipal University Ethics committee before the commencement of the study. Nasal swabs were collected from children of $6-$ 15 years old going to various schools of Udupi taluk, Karnataka, India. The names of the schools from where the samples were obtained cannot be disclosed due to ethical considerations. Sterile cotton swabs (Hi-Media, Mumbai) were used to collect the specimen and standard methods were followed to isolate the $S A^{9}$.

Inducible clindamycin resistance was detected among the SA isolates by $D$ test ${ }^{2}$. An erythromycin disk $(15 \mu \mathrm{g})$ was placed $15 \mathrm{~mm}$ (edge to edge) from a clindamycin disk (2 $\mu \mathrm{g})$ in a standard disk diffusion test (Figure 1). Muller Hinton agar medium was used for testing. A flattening of the zone of inhibition in the area between the disks where both drugs have diffused after 18-24 hours of incubation was considered to be inducible clindamycin resistance.

All the strains of SA were inoculated onto Muller Hinton Agar (MHA) containing $4 \%$ sodium chloride and $6 \mu \mathrm{g} / \mathrm{ml}$ of oxacillin. Growth of one or more colonies of Staphylococcus aureus in this medium was considered as MRSA. During antibiotic susceptibility testing, susceptibility to $30 \mu \mathrm{g}$ cefoxitin was also tested. A zone diameter of $\leq 19 \mathrm{~mm}$ was considered as resistance and confirmed as $\mathrm{MRSA}^{10}$. Statistical analysis to study the association between MRSA and inducible clindamycin resistance was carried out using SPPS version 16 .

\section{Results}

Out of the 378 isolates tested, 17 strains (4.1\%) were found to be resistant to cefoxitin in disk diffusion test and all those strains were grown on salted Muller Hinton agar (MHA) containing $6 \mu \mathrm{g} / \mathrm{ml}$ of oxacillin.

Among the SA, $11.6 \%$ (44/378) strains were showing inducible clindamycin resistance and other $88.4 \%$ strains were not showing positive D test.Among the MRSA, 71\% $(12 / 17)$ strains were MLSBi phenotype. When cross tabulation was done by Chi square test to know the significance of inducible clindamycin resistance among MRSA isolates, there was a statistically significant association noticed with $p<0.05$ (Table 1 ).

Table 1: MRSA and MLSBi resistance

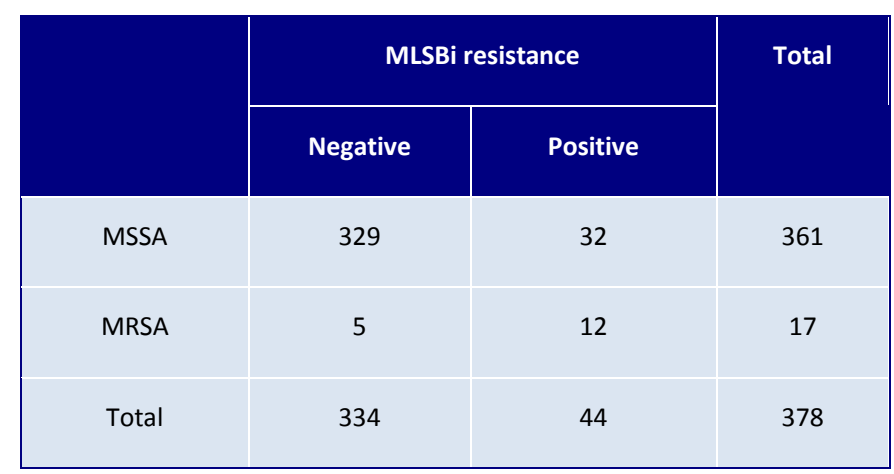

\section{Discussion}

The most widespread and clinically important resistance mechanisms encountered with gram-positive organisms are the production of methylases and efflux proteins. Resistance to MLSB antibiotics are the best examples. The clinical failure of clindamycin therapy has been reported before.Lewis JS in 2005 cited about the case report of Mc Geheeet al. as they found that poor prognosis in a case of erythromycin resistant SA infection after treating with lincomycin and clindamycin. This particular strain was susceptible to lincomycin and clindamycin in vitro testing but developed resistance during treatment ${ }^{11}$.

Such emerging strains that shows inducible clindamycin resistance among SA isolates is one of the major concerns for clinicians while choosing the appropriate antibiotic 
regimen. Hence, there is a need to identify the mechanisms that confer resistance to MLS antibiotics with regard to clindamycin therapy of staphylococcal infections.

Figure 1: Detection of inducible clindamycin resistance by D test

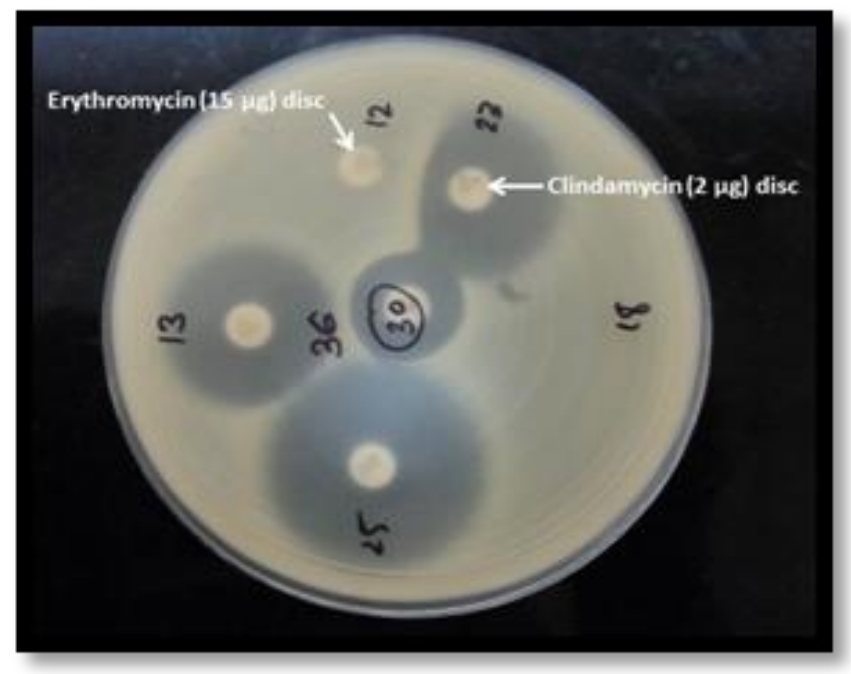

\section{Conclusion}

Routine investigations of MLSBi status would, therefore, be of great significance in the choice of antibiotics. The same holds good in the case of the colonizing strains as well. It needs to be emphasized here that, in the population investigated, a high incidence of inducible clindamycin resistance (71\%) was noticed among colonizing strains of MRSA. When the inducible clindamycin resistance crops up, a roughly 25 fold increase is registered in MRSA when compared with MSSA. This information about the MLSBi status among the colonizing strains would also help the public health authorities to plan and implement infection control strategies at the community level.

\section{Author's Contribution:}

All the authors were involved in designing the study, collecting and compiling the data; SG did the analysis of data, were involved in the data interpretation, and drafted the manuscript. Manuscript was revised by SG, CAM, IB. All the authors approved the final document.

\section{Acknowledgement}

I acknowledge Indian Council of Medical Research (ICMR) for funding a part of this work. I also acknowledge Dr. Asha Kamath, Associate Professor of community medicine, KMC, Manipal for helping in the statistical analysis.

\section{Conflict of interest:}

There is no conflict of interest among authors arising from the study.

\section{List of Abbreviations}

SA - Staphylococcus aureus

MRSA - Methicillin resistant Staphylococcus aureus

MLSB - Macrolides, lincosamides and streptogramin B

MHA - MullerHinton Agar

OR - odds ratio

\section{References}

1. Malay RS. Present scenario of antibiotic resistance in Staphylococcus aureus and its genetics. In: Arakere G, Raghunath D, editors. Staphylococcus aureus: Biology and infections, Recent developments. Bangalore: Macmillan: 2011. P. 110-130.

2. Lewis JS 2nd, Jorgensen JH. Inducible clindamycin resistance in Staphylococci: should clinicians and microbiologists be concerned? Clin Infect Dis. 2005 Jan 15;40(2):280-5.

http://dx.doi.org/10.1086/426894

PMid:15655748

3. Leclercq R. Mechanisms of resistance to macrolides and lincosamides: nature of the resistance elements and their clinical implications. Clin Infect Dis. 2002 Feb 15;34(4):48292.

http://dx.doi.org/10.1086/324626

PMid:11797175

4. Roberts MC, Sutcliffe J, Courvalin P, Jensen LB, Rood J, Seppala $H$. Nomenclature for macrolide and macrolidelincosamide-streptogramin B resistance determinants. Antimicrob Agents Chemother. 1999 Dec;43(12):2823-30. PMid:10582867 PMCid:PMC89572

5. Ross JI, Eady EA, Cove JH, Cunliffe WJ, Baumberg S, Wootton JC. Inducible erythromycin resistance in staphylococci is encoded by a member of the ATP-binding transport super-gene family. MolMicrobiol. 1990 Jul;4(7):1207-14.

http://dx.doi.org/10.1111/j.1365-2958.1990.tb00696.x PMid:2233255

6. Ross JI, Farrell AM, Eady EA, Cove JH, Cunliffe WJ. Characterisation and molecular cloning of the novel macrolide-streptogramin $B$ resistance determinant from Staphylococcus epidermidis. J Antimicrob Chemother. 1989 Dec;24(6):851-62.

http://dx.doi.org/10.1093/jac/24.6.851

PMid:2559912

7. Weisblum B. Erythromycin resistance by ribosome modification. AntimicrobAgents Chemother. 1995 Mar;39(3):577-85.

http://dx.doi.org/10.1128/AAC.39.3.577

PMid:7793855 PMCid:PMC162587

8. Werckenthin C, Schwarz S, Westh H. Structural alterations in the translational attenuator of constitutively expressed ermC genes. Antimicrob Agents Chemother. 1999 Jul;43(7):1681-5.

PMid:10390222 PMCid:PMC89343 
9. Duguid JP. Staphylococcus: cluster forming gram positive cocci. In: Colle JG, Duguid JP, Fraser AG, Marmion BP, editors.Mackie\& McCartney Practical medical micribiology. 13th edition. 2nd volume. London: Churchill livingstone; 1989. P. $303-16$.

10. CLSI. Performance Standards for Antimicrobial Susceptibility Testing, 19th Informational Supplement. M100-S19. Wayne, PA: Clinical and Laboratory Standards Institute. 2009.

11. McGehee RF, Barrett FF, Finland F. Resistance of Staphylococcus aureus to lincomycin, clindamycin and erythromycin. Antimicrob Agents Chemother1968; 13:392-7.

\section{Article Information}

\section{Article history}

\begin{tabular}{|l|l|}
\hline Received & $21^{\text {ST }}$ October 2013 \\
\hline Received in revised form & $12^{\text {th }}$ March 2014 \\
\hline Accepted & $20^{\text {th }}$ March 2014 \\
\hline
\end{tabular}

